\title{
Social Media Addiction, Resistance, and Influence of Awareness: Measurement of Psychology Students' Resistance to Facebook Addiction
}

\author{
Assist. Prof. Dr. Tutku Akter \\ Girne American University/ Northern Cyprus \\ E-mail: tutkuakter@gmail.com
}

\section{Doi:10.5901/mjss.2014.v5n8p456}

\begin{abstract}
Because of the development of communication technologies, some concepts particularly related to social sciences require to be redefined and renegotiated. The field of psychology is one of these social sciences, which has had its share from this progress. The emergence of new places for interaction and new aspects of socialization has resulted in varied factors influencing social identity construction. Academic associates are increasingly focusing on social network sites (SNSs), as one of such "spaces". Thus, most particularly, students of psychology-based departments have importance as they are the intended psychologists and psychological counsellors. Hence, for the purpose of the study, resistance of psychology students to Facebook, as a sort of social media, is measured by using Bergen's Facebook addiction scale (BFAS).
\end{abstract}

Keywords: social network sites (SNS), Facebook addiction, communication technologies, 'Salience', 'mood modification' and 'tolerance'

\section{Introduction}

Undoubtedly, the developing and changing world system that we are involved in influences every aspect of our lives. Not only in political, economic, or cultural sense but also changes especially in new technologies influence the psychology of people as well and the changes that it brings is the most common subject of researches.

Internet addiction and types of addiction that emerged via the developing communication technologies, is one of the most burning issues in the field of social sciences.

Social Networking, which is a means of social media, can be defined as "online place where a user can create a profile and build a personal network that connects him or her to other users" (Lenhart, A., \& Madden, M., 2007). People do use these sites to communicate, produce, and exchange meanings, improve social relationships, entertain or exchange data. It is also known that, nowadays, social network sites (SNS) play a critical role in providing information to its users and people mostly are dependent on social media for processing and gathering needed information.

Ellison (2007) defines social networking systems and claims that it allows individuals or its users to

(1) construct a public or semi-public profile within a bounded system, (2) articulate a list of other users with whom they share a connection, and (3) view and traverse their list of connections and those made by others within the system. The nature and nomenclature of these connections may vary from site to site

In terms of this definition, it is possible to assume that social media and SNSs provide its users a new platform to socialize and to interact. Being isolated from restrictions of embodiment, time, and space SNSs offer its users decentralized communication networks and opportunity to experience the globalized world.

However, it is essential to bear in mind that new technologies brought new risks as well. Especially lack of inspection, uncontrolled consumption of these technologies, and unrestrained time that is spent on them, may cause unintended consequences.

Additionally, it is noted that SNSs are popular online communication forms mostly among adolescents and emerging adults (Subrahmanyam, K., Reich, S. M., Waechter, N., \& Espinoza, G., 2008).

Within this context, the purpose of the present study will be to measure resistance of psychology students as young adults to the SNSs, particularly to Facebook addiction.

Because of this, a new psychological scale developed by Norwegian psychologists to measure Facebook addiction will be taken for granted. This novel measure is called the Bergen Facebook Addiction Scale (BFAS), and it consists of 18 items comprising three items for each of the six core elements of addiction (salience, mood modification, tolerance, withdrawal, conflict, and relapse), 
It is important to highlight that the present study is not about negotiating the influences of Facebook addiction on their career, in case of obtaining results, which indicate their overreliance. The basis of the study is to understand whether knowing or learning the negative influences of this kind of networking would affect addiction to Facebook or its usage.

\section{Literature Review}

This section looks at the definitions and discussions of communication systems, its influences on socialization process as providing new space for public sphere. In a narrower sense, the psychology of media usage as well as new age media will be explored within the context of new dimensions of addictions.

\subsection{Mass media and socialization process}

As is known, there are various definitions of communication in the literature. Briefly, it can be defined as "a two-way process in which there is an exchange and progression of ideas towards a mutually accepted direction or goal" (Kaul, 2000) which has three basic elements (sender, message, and receiver) and three articulative components (coding, interpreting, and feedback).

Communication can be categorized in terms of its effects (eg., Positive vs negative), direction, code system (written, verbal, nonverbal), correlation system, position of the units (horizontal vs vertical), and spatiotemporal peculiarities (face-to-face vs distance).

By the rapid development of communication technologies, especially through freedom from restrictions of time and space, some of the most known categorizations of communication have changed. In addition, space- and time-based changes have also influenced other sorts of classifications, such as correlation-based categorizations.

According correlation-based categorizations of communication, previously, it was possible to classify communication into four groups: intrapersonal communication, interpersonal communication, group communication (ingroup/out-group), and mass communication. Intrapersonal communication refers to the communication with oneself and the brain that "may serve as both a transmitter and receiver" (Barker, L.L. and Wiseman, G., 1966). In other words, it refers to "internal dialogue that occurs between the "I" and the "me"' (Cathcart, R and Gumpert, G., 1983).

On the other hand interpersonal communication signifies the communication process that involves production and exchange of meanings between two or more people, and in group communication, members of group as a social being are interactively attached to each other. Finally, mass communication, which is articulated to interpersonal and group communication in new age media, briefly can be explained as transmission of knowledge and distribution of meanings from particular groups to diffused audiences.

McQuail (1994) handled the term 'mass' and 'communication' separately to clarify conceptualization of 'mass communication'. He claimed that the term 'mass' conveys great volume, variety, whereas 'communication' denotes the exchange of meaning, transmission, and reception of the message. Thus the concept 'mass communication' can be defined as a process that encompasses the foundations and techniques by which particular groups employ technological means to distribute and spread symbolic content to widely diffused audiences (McQuail, 1994; Janowitz, 1968). It is also important to emphasize the fact that mass communication process, which is "involved with large audiences, frequent reproduction of messages and radip distribution of messages" (Fielding, 2005: 25), is not synonymous with mass media, which indicates the organized technologies that make mass communication possible.

Emerging communication technologies, undoubtedly, required the redefinition and reconceptualization of some terms especially in the field of communication. Some of the traditional definitions could not identify most of the concepts. These shortcomings are clearly visible in the classifications of communication. Especially features of new age media in spatial and temporal context, decentralization of information flow, as well as speed of interaction, and feedback necessitated rethinking traditional categorizations of communication.

On the significance of mass media, McQuail (1994) claimed that media, especially mass media, can be handled as a potential means of influence and control, and thus as a power resource; in addition, it can be used as an arena where many issues of public life are played out.

This new sphere of communication also provides an alternative arena for socialization, interaction, production, and exchange of meaning. Especially social networks, which are one of the communication tools of social media, opens up an opportunity for both online and offline as well as synchronized and asynchronized interaction between person(s). Barkhuus and Tashiro (2010) also claimed that social networks contribute significantly to casual socialization.

As is known, individuation and socialization are articulated to each one in some aspect. It is not possible to talk 
about socialization without dealing with individualization as it would not be possible to talk about individualization without socialization (Habermas, 1992). Also it is noted that both individualization and socialization continuously shapes individuals, and therefore the social relations. Regarding SNS (social media networks), it will be handled as a public phenomenon and as a notion that suggests an arena of exchange, similar to the ancient Greek agora.

By stating that "Television, popular newspapers, magazines and photography, the popular media of the modern period, are the public domain, the place where and the means by which the public is created and has its being" Hartley (1992:1) also emphasizes the argument that the media are the public sphere.

Kitchen (1988), one of the scholars who highlighted the changing aspect of communication by the rapid development of new technologies, has drawn attention to the change from centralized media to the decentralized one and features of the new age media by claiming

The glass screen of the computer was providing a window into the world where the patrons could explore their ideas and thought without fear of physical or mental retribution; true identities were hidden and patrons could participate without being visible member (Kitchen, 1988:76)

Even as new age media carries the ritual form of communication as well as characteristics of transmission, it enables people to experience the same things at the same time despite being at different places as well as enabling its users to find information, knowledge, and to participate in the public debate. It carries characteristics of interpersonal, group, and mass communication even as it brought the required reconceptualization of the SNSs.

Moreover, social media lead people to find ways of presenting themselves as well as providing them an environment to choose a community and participate with other members. Via this feature, as mentioned previously, it provides an arena for its users to socialize.

Many researches have pointed out the interrelation between social relations and habits as well as addictions (such as alcohol, drug abuse, etc).This new arena of socialization brought the necessity of conducting new researches about the changing addictions and habits that has shown up. Recent researches, especially in the field of psychology, mostly deals with the addiction of social media as a means of communication and new space for socialization.

Some of these researches, handled internet addiction as a pathological behavior, but declared that its symptoms may be found in normal populations, placing it within the possibility of conformist media attendance theories, when discussing Internet addiction in terms of the formation of media habits (Song, I., Larose, R., Eastin, M. S., \& Lin, C. A., 2004).

Because of this, the present study will basically focus on 'social media' as a new form of communication and opportunities as well as risks that it may bring with itself especially in the sociocultural and psychological aspects.

\subsection{Psychology of media and new age media: emerging risks}

Since the development of communication technologies, communication systems based on mediation via computer networks, particularly SNSs, became one of the most popular concepts within other mediated communication environments.

This expansion does not only improve and alter the self-formation process; it brings a new kind of intimacy into being, which did not exist before, and a novel understanding, which differs in particular fundamental respects from the forms of intimacy features of face-to-face interaction as well (Thompson, 1995; Suler, 2004).

Social networking sites refer to virtually constructed social relationships between individuals or users who share same the spatial-temporal practices. Virtual sites, which consist of SNSs, enable individuals to find opportunity of practicing "sense of disembodiment" as well as experiencing socialization, even as time and space lose their significance. As noted by Nayar (2010), disembodiment of a digitized body, reconstruction of personality, appearance, role, and manners into set of codes entered into databases, allows us to recover "another's personality, not necessarily by meeting him or her face to face but through a database" (p. 77).

It is noted by Larose, Kim, and Peng (2010) that as Internet fascinates and forms more varieties of entertainment such as games and interpersonal communication, it will be progressively more vital to draw differences amongst online activities. However, the authors, based on recent studies, defined SNSs as problematic, addictive, and habitual.

Furthermore, widespread use of SNSs, which began as computer-mediated communication, is not limited to computerization anymore, but has become portable by virtue of mobile technologies (Moss, 2009). Since its innovation, Facebook as one of the SNSs, has become extremely well-liked among people, particularly young generations.

Regarding the definition by Croll and Power (2009), social networks are "communities built around the 
interpersonal relationships of their members. By keeping track of who each participant knows-and how they know one another —each member creates a private community through a white list of known friends" (p.458).

Hence, opportunities offered within the sociocultural context can be declared as unquestionable. As Boyd and Ellison (2007) also stated, SNSs allocate their users to piece a public or semipublic profile together within a surrounding structure, even as conveying other users' lists with whom they share a connection (Boys \& Ellison, 2007; Marion \& Omotayo, 2011; Isa et. al. 2012). Within the system, it also enables its users to view as well as to navigate their list of connections and those made by other users.

Kuss and Griffiths (2011) define SNSs as an opportunity for virtual communities to set up personal public profiles, cooperate with real-life companions, and meet other people based on shared interests. Kuss and Griffiths conducted a research on whether 'addiction' to social networks on the Internet causes a potential mental health problem for some users or not.

Regarding the findings of their research, it is noted that SNSs were mostly used for social purposes, chiefly related to the upholding of established offline networks. Furthermore, the results indicated that extravert people use these sites for social improvement, whereas introvert people use it for social compensation. Negative correlates of SNS usage embrace the diminution in real-life social community participation, as well as relationship problems, each of which may be symptomatic of probable addiction.

Although studies on young users of SNSs are emerging, new research questions have also been raised considering the interrelation between demographic variables, particularly education level as an indicator of future occupations of these young people, and their usage of SNSs, as well as social networking addiction levels.

Moreover, cultural characteristics of the society that were involved in, assuming educational field as a demographic variable as a binding item, are provided as basis for the present study. Particularly graduate education, which sets its sight on educating knowledgeable and well-equipped individuals relevant to the field, aims to fit students into the working life by providing potential knowledge in detail regarding the field.

Within this context, just as students who study in the field of communication learn how mass media can change audiences into consumers and can be a sort of market place from the critical approach point of view, and correspondingly become educated on media literacy, students learn tips and details of the field they study.

Based on this, we can assume that psychology students, who will consult a number of individuals who will present several issues in the coming years, do learn feasible items that may influence the psychology of individuals whom they counsel. Particularly within the context of social psychology, students study how influential the social and cultural structures that they are in can be for individuals. In addition to this, effectiveness of coverage and the context of communication and communication process, which socialization owes to its realization, should also be studied in social psychology. This branch of psychology, particularly social psychology, can be defined as the scientific field that looks for understanding the nature and reason of individual's behavior, perception, and thoughts in social situations (Mynhardt, 2009; Husain, 1012; Baron, Byre, \& Branscombe, 2006; Christakis et. al. 2008).

There are numerous scientific findings that put forth those further risks, which are brought by developing communication technologies; freedom from spatial and temporal restrictions has changed the coverage and the context of the social environments, and thus the socialization process.

As Lui and Tsai (2012) declared

There's no doubt that we have enjoyed plenty of pleasure and benefited from online social networks. However, the drawbacks of online social networks inevitably appear, one of which is social isolation. Psychological well-being often refers to various measures that capture an individual's satisfaction with life. SNS captured the concentration of people and may lead to their social isolation, which has a negative effect on people's well-being. Scholars used a variety of scales that included measures of loneliness, depression, and overall life satisfaction (p. 5).

Losing touch with real world, restraining communicating in traditional ways, and the urge to not miss out on anything, has created an invisible layer of stress and pressure on the individuals, which are some of the risks or negative consequences of SNSs.

Caplan and High (2011) examined the relationship between Problematic Internet Use and the interpersonal functions of the Internet. They noted that social interaction in virtual environment differs from regular face-to-face communication in a significant manner, which can be particularly fascinating for those who show signs of problematic Internet use. It also differs in terms of offering greater anonymity, creating more time, and editing verbal messages, as well as offering more control over self-perception and impression management. As cited by Morahan-Martin (2007), negative outcomes regarding Internet use are using it for interpersonal activities and meeting people, forming 
relationships as well as seeking emotional supports.

In addition to this, Larose (2011) stated that there are a various clients who suffer from Internet addiction with specific intentions; this can take on multiple forms such as general pleasure-seeking behavior, using it as a means of entertainment, and as a means to fulfil social needs.

As claimed by Young, Yue, and Ying (2011), Caplan (2002) also dealt with technological addictions as a detachment of a behavioral addiction and stated that Internet addiction includes the main constituents of addiction such as salience, mood modification, tolerance, withdrawal, conflict, and relapse. Regarding Caplan's standpoint, Young et al. declared that Internet addicts do demonstrate a salience for the activity; they use Internet as a way to escape worrying or upsetting senses. They also do develop a tolerance for Internet to obtain pleasure and happiness; when they reduce Internet usage, they experience withdrawal. Apart from this, it is noted that they do suffer from increased conflicts with others because of their activity on the net. Finally, relapsing back to the Internet is explained as signs of addiction.

A new psychological scale to measure Facebook addiction developed by Norwegian psychologists is the first of its kind worldwide, which is adopted as is for the present study. This novel measure is the creation of Andraessen et al. University of Bergen, and is called the Bergen Facebook Addiction Scale (BFAS). This scale consists of 18 items comprising three items for each of the six core elements of addiction (salience, mood modification, tolerance, withdrawal, conflict, and relapse).

As mentioned earlier, this article aims to measure resistance of psychology students, (potential consultants various individuals in future), to the SNSs, particularly to Facebook addiction. This study will not negotiate the influences of Facebook addiction on their career, in case of obtaining results, which indicate their overreliance. The basis of the study is to understand whether knowing or learning the negative influences of this kind of networking would affect addiction to Facebook or its usage.

\section{Research Methodology}

\subsection{Participants}

A total of 119 undergraduates from 233 second-year psychology students of The American University voluntarily participated in the study. The average age among the sample was 23.5 years (standard deviation $(S D)=3.43$ ), and the sample comprised $50.4 \%$ men.

Sixty-nine percent of psychology students reported they very rarely spent time thinking about Facebook or planning use of Facebook (mean $(M)=1.75, S D=1.091, t(119)=17.48)$.

The majority (68\%) of participants reported that they very rarely feel they have to use Facebook increasingly to get the same pleasure from it ( $M=1.87, S D=1.26)$; they very rarely ( $55 \%)$ use Facebook to forget about their private problems $(M=2.18, S D=1.38)$; and they (69\%) very rarely use Facebook to reduce feelings of guilt, anxiety, helplessness, and depression $(M=1.92, S D=1.33)$. Besides this, $77 \%$ of the respondents claimed that they very rarely use Facebook to reduce restlessness $(\mathrm{M}=1.75, \mathrm{SD}=1.20)$.

In addition to this, $73 \%$ of psychology students very rarely have got warning from others about reducing use of Facebook $(M=1.76, S D=1.18)$. Only $8 \%$ of respondents decided to use Facebook less frequently and could not manage to do so $(M=1.84, S D=1.21)$. Only $11 \%$ of them noted that they become irritable in case of being prohibited from using Facebook ( $\mathrm{t}(119)=16.08, \mathrm{M}=1.94, \mathrm{SD}=1.31$ ) and a small number of them (7\%) reported that they feel bad very often when they cannot log on to Facebook for sometime $(M=2.06, S D=1.22)$.

\subsection{Instrument}

For the purpose of the study, BFAS was posted on the Facebook wall of the psychology students $(\mathrm{N}=233)$, and they were asked to fill the scale. Participants rated each of the 18 items on a 5-point Likert-type scale, ranging from 1 (very rarely) to 5 (very often). The BFAS demonstrated high internal reliability in the current study $(a=0.95)$.

Recent frequency of Facebook addiction test, which was based on BFAS, was measured with a 5-point Likert item ("I think about Facebook even when I am not online") with the following response options: 1 = "very rarely," 2 = "rarely," $3=$ "sometimes," 4 = "often," and 5 = "Very often". The scale consists of 18 main items that are categorized under six main statements as; salience, mood modification, withdrawal, tolerance, conflict, and relapse (Andreassen et al. 2012).

The scale was posted on the second-year psychology students' Facebook profile page and they were asked to respond to the research regarding volunteerism principle. For a month, data entry was allowed. The majority of participants reported that they had completed the survey in 5 min or less. Compatible with the purpose of the study, 
frequency analyses were conducted to characterize the percentages and distributions, and one sample t-tests were used to determince standard deviations and means as well as difference of freedom scores. Pearson correlations and linear regression equations were computed to assess the reciprocations between each score and determine significances of Facebook use.

\section{Findings and Discussion}

\subsection{Descriptive statistics of 'Salience', 'mood modification', 'withdrawal', 'tolerance', 'conflict', and 'relapse statements'}

Regarding the descriptive statistics of 'salience' and 'mood modification' statement, it is noted that 'Thinking a lot about what was happened on FB recently' when they are not online was noted as the most prominent 'salience' statement (2,61 $\pm 1,40$ ), whereas 'spending more time on Facebook than initially intended' was classified as the outstanding 'mood modification' $(2,39 \pm 1,23)$.

Besides this, 'using Facebook to forget about private problems' is noted as a basic indicator of 'withdrawal" (2, 18 $\pm 1,37)$, 'deciding to use FB less frequently but not managing to do' was the leading attitude in the context of 'tolerance' $(1,84 \pm 1,21)$, 'feeling bad unless log on to FB for sometime' is noted as the main account of 'conflict', whereas 'giving less priority to hobbies, leisure activities and exercise because of Facebook' was the most prominent 'relapse' statement within the list.

\subsection{Reciprocal relationship between constituents of addiction: 'Mood modification', 'salience', 'tolerance' 'withdrawal', 'conflict', and 'relapsing':}

According to the results, it is noted that mood modification of the psychology students significantly correlated with their withdrawal methods, tolerance of using Facebook, inner conflict, and salience about Facebook usage (see Table 1 for a complete list of correlates).

It is clarified that spending more time on Facebook than initially intended has a significant correlation with using it to reduce feelings of guilt, anxiety, helplessness, and depression [withdrawal] $(r=0.47)$, deciding to use Facebook less frequently but not being able to manage it [tolerance] $(r=0.53)$, becoming restless or troubled in case of being prohibited from using Facebook [conflict] ( $r=0.59)$, and spending a lot of time thinking about Facebook or planning use of Facebook [salience] $(r=0.59)$.

TABLE 1. Correlations regarding to 'Mood modification': Statements of 'salience', 'tolerance' 'withdrawal' 'conflict' and 'relapse'

\begin{tabular}{|c|c|c|c|c|c|c|c|c|c|c|c|c|c|}
\hline & & $\begin{array}{l}\text { [withdra } \\
\text { wl] } \\
\text { I use FB } \\
\text { to forget } \\
\text { about } \\
\text { private } \\
\text { problem } \\
\text { s. }\end{array}$ & $\begin{array}{l}\text { I used FB } \\
\text { to reduce } \\
\text { feelings of } \\
\text { guilt, } \\
\text { anxiety, } \\
\text { helpless, } \\
\text { and } \\
\text { depression }\end{array}$ & $\begin{array}{l}\text { I used FB } \\
\text { in order to } \\
\text { reduce } \\
\text { restless }\end{array}$ & $\begin{array}{l}\text { [tolerance] } \\
\text { I have } \\
\text { experienced } \\
\text { that others } \\
\text { have told me } \\
\text { to reduce } \\
\text { my use of } \\
\text { FB but not } \\
\text { listened } \\
\text { them }\end{array}$ & $\begin{array}{l}\text { I have tried } \\
\text { to cut back } \\
\text { on my } \\
\text { visits } \\
\text { without } \\
\text { succeeding }\end{array}$ & $\begin{array}{l}\text { Idecided } \\
\text { to use FB } \\
\text { less } \\
\text { frequently } \\
\text { butnoy } \\
\text { managed } \\
\text { to do so }\end{array}$ & $\begin{array}{c}\text { [conflict] } \\
\text { Become } \\
\text { restless or } \\
\text { troubledif } \\
\text { I have } \\
\text { been } \\
\text { prohibited } \\
\text { from using } \\
\text { FB }\end{array}$ & $\begin{array}{c}\text { Become } \\
\text { irritable if I } \\
\text { have been } \\
\text { prohilibited } \\
\text { from using } \\
\text { FB }\end{array}$ & $\begin{array}{l}\text { I felt bad } \\
\text { if I, for } \\
\text { different } \\
\text { reasons, } \\
\text { could not } \\
\text { log on to } \\
\text { FB for } \\
\text { sometime }\end{array}$ & $\begin{array}{c}\text { [salience] } \\
\text { I spend a } \\
\text { lot of time } \\
\text { thinking } \\
\text { about FB } \\
\text { or } \\
\text { planning } \\
\text { your use } \\
\text { of FB. }\end{array}$ & $\begin{array}{l}\text { I thought } \\
\text { about } \\
\text { how I } \\
\text { could } \\
\text { free } \\
\text { more } \\
\text { time to } \\
\text { spent on } \\
\text { FB }\end{array}$ & $\begin{array}{l}\text { Thought } \\
\text { a lot } \\
\text { about } \\
\text { what has } \\
\text { happened } \\
\text { on FB } \\
\text { recently }\end{array}$ \\
\hline \multirow[t]{3}{*}{$\begin{array}{l}\text { Spending } \\
\text { more time on } \\
\text { FB than } \\
\text { initially } \\
\text { intended }\end{array}$} & \begin{tabular}{|l} 
Pearson \\
Correlatio \\
n
\end{tabular} &, $407\left({ }^{2 x}\right)$ &, $471\left(^{(2)}\right)$ &, $410\left({ }^{\infty}\right)$ &, $428\left({ }^{2}\right)$ &, $422\left({ }^{+\infty}\right)$ &, $525\left({ }^{(x)}\right)$ & 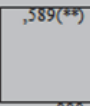 &, $407\left({ }^{+\infty}\right)$ &, $537\left({ }^{2}\right)$ &, $593\left({ }^{+\infty}\right)$ &, $398\left({ }^{2}\right)$ &, $327\left({ }^{2}\right)$ \\
\hline & $\begin{array}{l}\text { Sig (2- } \\
\text { tailed) }\end{array}$ &, 000 &, 000 &, 000 &, 000 &, 000 &, 000 &, 000 &, 000 &, 000 &, 000 &, 000 &, 000 \\
\hline & $\mathrm{N}$ & 119 & 119 & 119 & 119 & 119 & 119 & 119 & 119 & 119 & 119 & 119 & 119 \\
\hline \multirow[t]{3}{*}{$\begin{array}{l}\text { Feeling an } \\
\text { urge to use } \\
\text { FBmore and } \\
\text { more }\end{array}$} & $\begin{array}{l}\text { Pearson } \\
\text { Correlatio } \\
\text { n }\end{array}$ & , आI(स) &, $475\left({ }^{8}\right)$ &, $405\left(^{85}\right)$ &, $559($ क्ष) &, $549\left({ }^{83}\right)$ & ,607(स्क) &, $610\left({ }^{25}\right)$ &, $540\left({ }^{38}\right)$ &, $564(25)$ &, $680(25)$ &, $677(85)$ &, $614(85)$ \\
\hline & \begin{tabular}{|l} 
Sig (2- \\
tailed)
\end{tabular} &, 001 &, 000 &, 000 &, 000 &, 000 &, 000 &, 000 &, 000 &, 000 &, 000 &, 000 &, 000 \\
\hline & N & 119 & 119 & 119 & 119 & 119 & 119 & 119 & 119 & 119 & 119 & 119 & 119 \\
\hline \multirow[t]{3}{*}{$\begin{array}{l}\text { Feelling } \\
\text { necessityto } \\
\text { use FB more } \\
\text { and more in } \\
\text { order to get } \\
\text { the same } \\
\text { pleaseure }\end{array}$} & \begin{tabular}{|l} 
Pears on \\
Correlatio \\
n
\end{tabular} &, $\left.500{ }^{8}{ }^{8}\right)$ &, $521\left({ }^{8}\right)$ &, $368\left({ }^{25}\right)$ &, $558\left({ }^{8}\right)$ &, $453\left({ }^{8}\right)$ &, $592\left({ }^{25}\right)$ &, 665 (2) $^{2}$ &, $570\left({ }^{8}\right)$ &, $563\left({ }^{85}\right)$ &, $743\left({ }^{+2}\right)$ &, $598(89)$ & $480\left({ }^{20}\right)$ \\
\hline & $\begin{array}{l}\text { Sig (2- } \\
\text { tailed) }\end{array}$ &, 000 &, 000 &, 000 &, 000 &, 000 &, 000 &, 000 &, 000 &, 000 &, 000 &, 000 &, 000 \\
\hline & $\mathrm{N}$ & 119 & 119 & 119 & 119 & 119 & 119 & 119 & 119 & 119 & 119 & 119 & 119 \\
\hline
\end{tabular}


Additionally, feeling an urge to use Facebook increasingly is another mood modification significantly correlated with reducing the feelings of guilt, anxiety, helplessness, and depression [withdrawal] $(r=0.48)$, deciding to use Facebook less frequently but not being able to manage it [tolerance] $(r=0.61)$, becoming restless or troubled in case of being prohibited from using Facebook [conflict] $(r=0.61)$, and spending a lot of time thinking about Facebook or planning use of Facebook [salience] ( $r=0.68)$.

Likewise, feeling that they had to use Facebook increasingly to get the same pleasure from it has also a significant correlation with using it to forget private problems [withdrawal] ( $r=0.50)$, deciding to use Facebook less frequently but not being able to manage it [tolerance] $(r=0.59)$, becoming restless or troubled in case of being prohibited from using Facebook [conflict] $(r=0.67)$, and spending a lot of time thinking about Facebook or planning use of Facebook [salience] $(r=0.74)$.

\subsection{Correspondence between increased 'conflicts' with others, experiencing 'withdrawal' even as reducing Internet use and 'relapsing' back to the internet:}

Regarding the findings related to correlations of 'conflict' with 'withdrawal' and 'relapse' (see Table 2 for a complete list of correlates), it is noted that becoming restless or troubled in case of being prohibited from using Facebook has a significant correlation with using Facebook to reduce feelings of guilt, anxiety, helplessness, and depression $(r=0.63, p$ $\leq 0.01)$ as well as ignoring their partner, family members, or friend because of Facebook ( $r=0.74)$.

Table 2. Correlations of 'conflict' with 'withdrawal' and 'relapse'

\begin{tabular}{|c|c|c|c|c|c|c|c|}
\hline & & \begin{tabular}{c|} 
[withdrawl] \\
Iuse Facebook \\
to forget about \\
private \\
problems.
\end{tabular} & $\begin{array}{l}\text { [withdrawl] } \\
\text { I used FB to } \\
\text { reduce feelings of } \\
\text { guilt, anxiety, } \\
\text { helpless, and } \\
\text { depression }\end{array}$ & $\begin{array}{c}\text { [withdrawl] } \\
\text { I used FB ýn } \\
\text { order to reduce } \\
\text { restless }\end{array}$ & $\begin{array}{l}\text { [relapse] } \\
\text { I used FB so much } \\
\text { that it had a negative } \\
\text { impact on my } \\
\text { job/studies }\end{array}$ & $\begin{array}{c}\text { [relapse] } \\
\text { I gave less priority to } \\
\text { hobboes, leisure } \\
\text { activites and exercise } \\
\text { because of FB }\end{array}$ & $\begin{array}{c}\text { [relapse] } \\
\text { I ignored my partner, } \\
\text { family members, or } \\
\text { friends becasue of FB }\end{array}$ \\
\hline \multirow{3}{*}{$\begin{array}{l}\text { [conflict] Become } \\
\text { restless or troubled if } \\
\text { I have been prohibited } \\
\text { from using FB }\end{array}$} & Pearson Correlation & $541\left({ }^{* *}\right)$ &, $626\left(^{* *}\right)$ & $527\left({ }^{* *}\right)$ &, $568\left({ }^{* *}\right)$ & $557(* *)$ &, $737\left({ }^{* *}\right)$ \\
\hline & Sig. (2-tailed) &, 000 &, 000 &, 000 &, 000 &, 000 &, 000 \\
\hline & $\mathrm{N}$ & 119 & 119 & 119 & 119 & 119 & 119 \\
\hline \multirow{3}{*}{$\begin{array}{l}\text { [conflict] Become irritable } \\
\text { ifI have been prohibited } \\
\text { from using FB }\end{array}$} & Pearson Correlation &, $511\left({ }^{* *}\right)$ & $626\left({ }^{* *}\right)$ &, $448\left({ }^{* *}\right)$ &, $547\left({ }^{* *}\right)$ &, $449\left({ }^{* *}\right)$ & $475\left({ }^{* 2}\right)$ \\
\hline & Sig. (2-tailed) &, 000 &, 000 &, 000 &, 000 &, 000 &, 000 \\
\hline & $\mathrm{N}$ & 119 & 119 & 119 & 119 & 119 & 119 \\
\hline \multirow{3}{*}{$\begin{array}{l}\text { [Conflict] I felt bad if } I \text {, for } \\
\text { different reasons, } \\
\text { could not log on to } \\
\text { FB for sometime }\end{array}$} & Pearson Correlation &, $522\left({ }^{\circ}\right)$ &, $612\left({ }^{* 3}\right)$ & ,491(ल) &, $\left.603{ }^{85}\right)$ & ,593(ल) &, $678(8 \times)$ \\
\hline & Sig. (2-tailed) &, 000 &, 000 &, 000 &, 000 &, 000 &, 000 \\
\hline & $N$ & 119 & 119 & 119 & 119 & 119 & 119 \\
\hline
\end{tabular}

Besides this, becoming irritable in case of being prohibited from using Facebook has a significant correlation with using Facebook to reduce feelings of guilt, anxiety, helplessness, and depression $(r=0.63)$ and using Facebook so much that it had a negative impact on their job/studies $(r=0.56)$.

As a final point, results indicated that feeling bad in case of not being able to log on to Facebook for sometime has significant correlation with using Facebook to reduce feelings of guilt, anxiety, helplessness, and depression as well $(r=0.62)$, and with ignoring their partner, family members, or friend because of Facebook $(r=0.68)$.

\subsection{Reciprocal connection between 'salience' and 'tolerance' for Internet}

Finally, according to findings, spending a lot of time thinking about Facebook or planning to use it has a significant correlation with experiencing others telling to reduce Facebook usage but not listening to them $(r=0.58, p \leq 0.01)$, trying to cut back on visits without succeeding $(r=0.54)$, and deciding to use Facebook less frequently but not being able to manage $(r=0.68)$ (Table 3). 
Table 3. Correlation of 'salience' with 'tolerance'

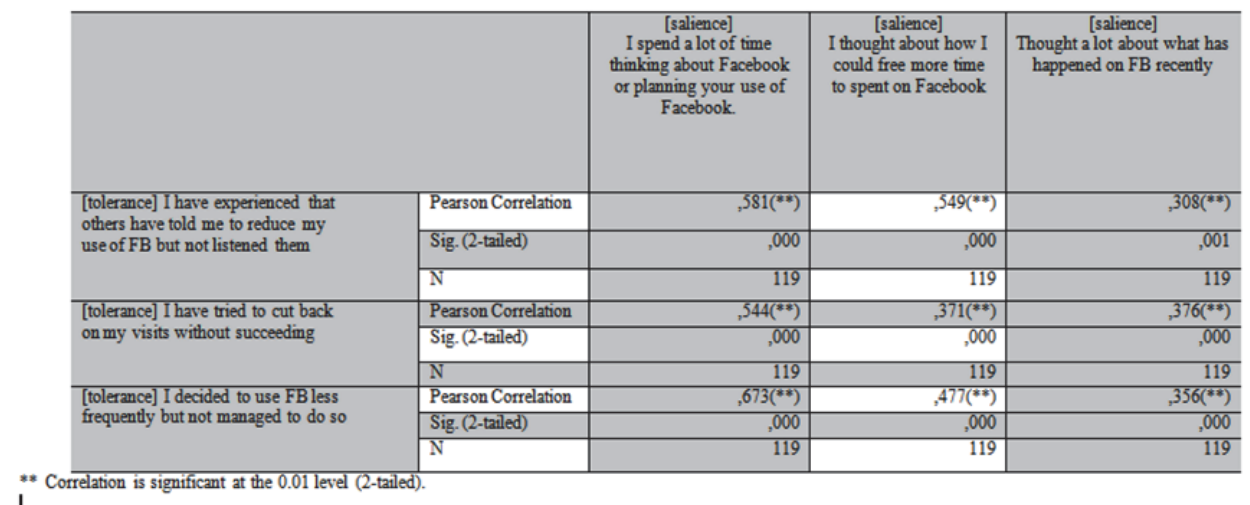

\section{Concluding Remarks}

The present study investigated whether psychology students as future psychological counsellors are potential Facebook addicts or not. Regarding the findings, it is noted that although not being addictive, there are significant correlations between six main constituents of addiction noted by Young, Yue, and Ying (2011); salience, mood modification, withdrawal, tolerance, conflict, and relapse.

Caplan's standpoint, which claims that Internet addicts do demonstrate a salience for the activity and use Internet as a way to escape worrying or upsetting senses, was legitimated once again.

It is also noted that participants do develop a tolerance for Internet to get pleasure and happiness even if they are not Internet addicts; as they reduce Internet use, they may experience withdrawal.

It is also clarified that participants may suffer from increased conflicts with others because of their activity on the net and relapsing back to the Internet can be noticed.

Results indicated that having knowledge about negative influences of using social media too much can be assumed as a disincentive factor for being addictive but not necessarily mean that addiction features cannot be detected. Similar to results of Yu et al. (2012), the findings of the present study show that Facebook concern has a low but positive correlation with features of addiction. As a result of this, purposes and reasons of using Internet do not differ among Internet addicts, but perhaps the frequency varies.

\section{References}

Andreasen, C. S., Torsheim, T., Grunborg, G. S and Pallesen, S. (2012). Development of a Facebook Addiction Scale. Psychological Reports, 110(2), pp.501-517

Barker, L. L., \& Wiseman, G. (1966). A model of intrapersonal communication.Journal of Communication, 16(3), 172-179.

Barkhuus, L., \& Tashiro, J. (2010, April). Student socialization in the age of facebook. In Proceedings of the SIGCHI Conference on Human Factors in Computing Systems (pp. 133-142). ACM.

Baron, R. A., Byre, D. \& Branscombe, N. R. (2006). South African Supplement to Social Psychology. 11 ${ }^{\text {th }}$ Ed. South Africa: Pearson.

Boyd, D and Ellison, N. B. (2007). Social Network Sites: Definition, History, and Scholarship. Journal of Computer mediated communication. Volume 13, Issue 1, pp. 210-230.

Caplan, S. E. and High, A. C. (2011). Online Social Interaction, Psychosocial Well-being and Problematic Internet Use. In Internet addiction : a handbook and guide to evaluation and treatment. Ed. by K. S. Young. Hoboken, NJ: Wiley.

Cathcart, R., \& Gumpert, G. (1983). Mediated interpersonal communication: Toward a new typology. Quarterly Journal of Speech, 69(3), 267-277.

Croll, A. \& Power, S. (2009). Complete Web Monitoring. Beijing: O'Reilly.

Ellison, N. B. (2007). Social network sites: Definition, history, and scholarship.Journal of Computer-Mediated Communication, 13(1), 210-230.

Fielding, M., \& Fielding, M. (2005). Effective communication in organisations: [preparing messages that communicate]. Lansdowne, Cape Town: Juta Academic.

Habermas, J. (1992). Postmetaphysical thinking: Philosophical essays(W. M. Hohengarten, Trans.). Cambridge, MA: MIT Press.

Hartley, J. (1992). The politics of pictures: The creation of the public in the age of popular media. Psychology Press.

Husain, A. (2012). Social Psychology. India: Pearson Education 
Kaul, A. (2003). Effective business communication. New Delhi: Prentice-Hall of India.

Kitchen, R. (1988). "Cyberspace, Culture and Society". Cyberspace. NewYork: John Wiley \& Sons.

Kuss, D. J. and Griffiths, M. D. (2011). Online Social Networking and Addiction-A Review of the Psychological

Literature. International Journal of Environmental Research and Public Health 2011, 8, pp. 3528-3552

Larose, R., Kim, J. and Peng, W. (2010). Social Networking: Addictive, Compulsive, Problematic or Just Another

Media Habit? In a Networked Self: Identity, Community and Culture on Social Network Sites. Ed. by Z. Papacharissi. New York:Routledge.

Larose. R. (2011). Uses and Gratifications of Internet Addiction. In Internet addiction : a handbook and guide to evaluation and treatment. Ed. by K. S. Young. Hoboken, NJ : Wiley.

Lenhart, A., \& Madden, M. (2007). Social networking websites and teens: An overview (p. 10). Pew/Internet.

Lewis, A., Kaufmana, J., Gonzalez, M., Wimmer, A. and Christakis, N. (2008). Tastes, ties, and time: A new social network dataset using Facebook.com. In Social Networks 30 (2008) 330-342.

Lui, Y and Tsai, Y. R. (2012). The impact of social networking services (SNS) on college students' social relationship and private life. International Journal of Arts and Commerce. Vol. 1 No. 4 September 2012

Marion, A. and Omotayo, O. (August 2011). Development of a social networking site with a networked Library and conference chat. Journal of Emerging Trends in Computing and Information Sciences. Volume 2, No 8.

Moss, S. (2009). The Entertainment industry: An Introduction. Wallingford: CABI.

Mynhardt, J. C. (2009). South African Supplement to social psychology. Cape Town: Pearson

Nayar, P. K. (2010). An introduction to new media and cybercultures. Chichester, West Sussex, U.K. ; Malden, MA : Wiley-Blackwell.

Song, I., Larose, R., Eastin, M. S., \& Lin, C. A. (2004). Internet gratifications and Internet addiction: On the uses and abuses of new media.CyberPsychology \& Behavior, 7(4), 384-394.

Subrahmanyam, K., Reich, S. M., Waechter, N., \& Espinoza, G. (2008). Online and offline social networks: Use of social networking sites by emerging adults. Journal of Applied Developmental Psychology, 29(6), 420-433.

Suler, R. (2004). The Final Showdown between In-Person and Cyberspace Relationships. In The Psychology of Cyberspace. http://users.rider.edu/ suler/psycyber/showdown.html\#intro [march, 2013]

Thompson, J. B. (1995). The media and modernity : a social theory of the media. Stanford, CA : Stanford University Press, 1995.

Wan Malini Wan Isa, W. M. W., Rozaimee, A.,Hassan, H. and Tahir, I. M. (March, 2012). Investigating the Patterns of Social Network Sites (SNS) Usage among Business Students. In Universal Journal of Management and Social Sciences. Vol. 2, No.3.

Young, Yue and Ying (2011). Prevalence Estimates and Etiologic Models of InternetAddiction. In Internet addiction: a handbook and guide to evaluation and treatment. Ed. by K. S. Young. Hoboken, NJ : Wiley.

Yu, S. C., Hsu, W. H., Yu, M. N. \& Hsu, H. Y. (2012). Is the use of Social Networking Sites Correlated with Internet Addiction? Facebook Use among Taiwanese College Students. In World Academy of Science, Engineering and Technology, V. 68 